\title{
O JOGO NAS AULAS DE EDUCAÇÃO FíSICA E SUAS IMPLICAÇÕES NO DESENVOLVIMENTO MORAL
}

\author{
Alessandra Caetano \\ Universidade Estadual de Campinas, Campinas, São Paulo, Brasil
}

\begin{abstract}
Resumo
Este trabalho investigou o desenvolvimento do jogo nas aulas de Educação Física em turmas de $5^{\circ}$ ano do Ensino Fundamental no Município de Valinhos - SP, e suas contribuições para o desenvolvimento da moralidade nos alunos. Foi realizada pesquisa qualitativa. Por meio das observações de aulas constatou-se que o jogo foi trabalhado com diferentes enfoques. Os professores lidavam com as regras de forma mais ou menos diretiva e a sua exposição com pouca ou nenhuma abertura para os alunos. Foram feitas intervenções, porém não houve aproveitamento das oportunidades para estímulo do desenvolvimento moral dos alunos. Considerou-se que mesmo o jogo sendo tratado nas aulas, as oportunidades oferecidas ao desenvolvimento moral dos alunos foram pouco aproveitadas.
\end{abstract}

Palavras chave: Educação Física Escolar. Jogo. Desenvolvimento Moral. Conflitos Interpessoais.

\section{Introdução}

Nas aulas de Educação Física (EF), muitos temas, conteúdos e saberes devem ser investigados, vivenciados, sistematizados, estudados, enfim, ressignificados, e o jogo é um deles.

O jogo é uma invenção humana que pode modificar "imaginariamente" a realidade, conseguindo, por muitas vezes, "encantar" as crianças. Por meio do jogar, elas podem explorar o mundo e suas possibilidades, de maneira espontânea e divertida, desenvolvendo suas capacidades cognitivas, motoras, afetivas e sociais. Pode ser considerado um fenômeno pertencente à cultura corporal, uma forma de linguagem, e é também um conteúdo muito presente na educação e nas pesquisas sobre desenvolvimento humano.

$\mathrm{O}$ objetivo do presente estudo é investigar o jogo em aulas de EF de $5^{\circ}$ ano e sua relação com o desenvolvimento moral dos alunos. Como objetivos específicos analisamos: como são tratadas as regras dos jogos durante as aulas; o enfoque dado ao jogo pelo professor; e a forma de resolução de conflitos durante os jogos por parte do professor.

\section{Revisão}

Pensar a Prática, Goiânia, v. 17, n. 3, p. 783-799, jul./set. 2014 


\section{O desenvolvimento moral}

Moralidade diz respeito à forma como são compreendidas e tratadas regras e normas. Segundo Piaget (1994) nem sempre a compreensão das regras acompanha a sua prática. A fim de compreender este processo, o autor estudou a prática e a consciência das regras em situação de jogo. Segundo Piaget, a prática das regras caracteriza-se pela "maneira pela qual as crianças de diferentes idades as aplicam efetivamente" (p.24). Já a consciência da regra caracteriza-se pela "maneira pela qual às crianças de diferentes idades se apresentam o caráter obrigatório, sagrado ou decisório, a heteronomia ou a autonomia inerente às regras do jogo" (p.24).

Segundo o mesmo autor (1994), a criança aprende a respeitar as regras ou normas morais vivendo em sociedade. A forma como as crianças lidam com as regras do jogo é a forma como elas lidam com as regras em geral, o que reflete seu desenvolvimento moral.

Vinha (1999) afirma que o desenvolvimento moral refere-se ao desenvolvimento das crenças, dos valores, das ideias sobre a noção do certo, do errado, dos juízos. Acrescentando, Severino (2005, p.139) propõe que "Os usos, os costumes, as práticas, os comportamentos, as atitudes que carregam consigo essas características e que configuram o agir dos homens nas mais diferentes culturas e sociedades constituem a moral."

É possível reconhecer a importância do contexto, das interações estabelecidas com ele e com o outro (indivíduo) e, ainda, a alternância de papéis experienciada neste processo. A escola revela-se como espaço de grandes possibilidades para proporcionar o desenvolvimento moral dos seus educandos, pelas possibilidades de interações que oferece. "É no contexto da convivência que se abre para ele todas as possibilidades, mas também se impõem os limites e as normas." (GOERGEN, 2005, p.1007).

Piaget afirma que o direito à educação não é apenas o frequentar a escola, mas também encontrar nessas escolas um ambiente propício para o desenvolvimento intelectual e moral dos educandos.

$\mathrm{Na}$ instituição escolar constata-se a construção da moral, ou das relações morais, acontecendo em diversos momentos e espaços físicos. Não há como evitar, ao educar, a formação do ser moral, uma vez que faz parte da dimensão humana. A qualidade do ambiente sociomoral influencia na construção de valores, atitudes e na formação moral. (PALMA, 2009, p.54)

Pensar a Prática, Goiânia, v. 17, n. 3, p. 783-799, jul./set. 2014 
Jogo

O jogo “[...] É um espaço de socialização, de domínio da relação com o outro, de apropriação da cultura, de exercício da decisão e da invenção.” (BROUGÈRE, 2001, p.103).

Huizinga (1980) caracteriza este fenômeno como sendo uma atividade espontânea, frívola, voluntária, que cria uma ordem nos contextos e que gera incertezas. Se o jogo gera incerteza, gera também tensão. Huizinga (1980) e Freire (2005) concordam que em meio a um jogo a imprevisibilidade é um fator presente e propício à aprendizagem. Relacionando os jogos nas aulas de EF, não se pode afirmar como eles vêm sendo trabalhados pelos professores. O jogo tem potencial para estimular o desenvolvimento das crianças. Jogado com suas regras, com o respeito às mesmas e também com o respeito pelo outro que joga, deve ser conduzido pelo professor e, dependendo das situações que compõem o contexto da aula, isso pode favorecer o desenvolvimento moral.

\section{Método}

Foi realizado estudo qualitativo, a partir de observações de aulas de EF de turmas $5^{\circ}$ ano da Rede Municipal de Ensino de uma cidade do interior do Estado de São Paulo. Foram observadas seis aulas, de três professoras diferentes, duas ministradas por cada uma. As observações de aulas foram registradas simultaneamente em um diário de campo (DC).

Os dados foram organizados e analisados a partir da triangulação de dados (MINAYO, 2010), que consiste no cruzamento de informações obtidas na fase exploratória com o que foi verificado na pesquisa de campo, juntamente com a análise propriamente dita.

O estudo foi aprovado pelo Comitê de Ética em Pesquisa sob o parecer de número 481/2011.

\section{Resultados}

Os dados obtidos nas observações realizadas foram organizados em categorias. A primeira categoria - Situações envolvendo habilidades dos alunos - foi elencada a partir de situações observadas na Escola 2 (E2) referentes à falta de habilidade das alunas durante a atividade proposta. A professora não fez intervenções para amenizar o desconforto e proporcionar um entendimento da tarefa a ser cumprida no jogo, além disto, os meninos culparam as colegas pela não obtenção de pontos, motivos que levaram algumas das alunas a desistirem da atividade. "Quando apareceram duplas de

Pensar a Prática, Goiânia, v. 17, n. 3, p. 783-799, jul./set. 2014 
meninas para realizar a tarefa, percebia-se que elas tinham muita dificuldade nas habilidades solicitadas (controle de bola e passe para o amigo)". (DCE2)

No jogo, em especial o competitivo, as habilidades (ou a falta delas) manifestam-se de maneira evidente. Por tratar-se de uma disputa, há o interesse em ganhar e a presença de um colega menos habilidoso na equipe pode atrapalhar essa meta. No ambiente educativo onde os alunos estão aprendendo novos saberes e sendo estimulados no seu desenvolvimento, será que a busca da vitória deve superar o interesse pela participação do colega? Quais valores se apresentam ao privilegiar o ganho de um jogo com a exclusão de algum companheiro? O jogo permite uma reflexão sobre o potencial de trabalho com esses valores morais.

Diante da exposição das habilidades, cabe ao professor estimular o respeito pelas diferenças e a tolerância com os menos habilidosos e também atitudes cooperativas entre todos, aproveitando da maior habilidade de alguns para auxílio dos outros. As ações devem ser planejadas de forma a incluir todos os alunos. Momentos de reflexão sobre práticas e sentimentos vivenciados durante as aulas podem colaborar para o estabelecimento de um clima de confiança entre todos e de valorização das opiniões pessoais.

No caso observado, as meninas não manifestaram o seu descontentamento e o espaço para discussão não foi aberto pela docente. Faz-se necessário discutir a ação dos alunos que se excluem sem lutar por garantir seu lugar, ou, que desistem após tentativas frustradas de obtê-lo, ou seja: o professor deve conduzir os alunos a partir dessas reflexões para que haja conscientização sobre as dificuldades.

Para Freire (2005), existem efeitos positivos nos novos desafios, mesmo sem êxitos imediatos e consecutivos, mas com a atitude do buscar, refletir e estimular para o crescimento dos educandos.

Na mesma escola outra situação foi observada:

Os meninos continuavam dominando as situações de ataque e as meninas praticamente sem participação. Até que a professora fez a alteração numa regra: a partir daquele momento os passes tinham que ser alternados (um menino e uma menina) e o chute em direção ao cone do adversário deveria ser dado por uma menina. Os meninos não gostaram, e um deles logo comentou: "- Ah professora, elas ficam conversando e não fazem nada". Ninguém mais comentou sobre isso, nem as meninas e nem a professora. (DC-E2).

Pensar a Prática, Goiânia, v. 17, n. 3, p. 783-799, jul./set. 2014 
Aqui vemos que mudança(s) gera(m) ansiedade e reações diversas nas pessoas, sejam elas crianças na escola ou adultos na sua vida diária. Os alunos receberam a mudança da professora e não questionaram o porquê da alteração; se anteciparam comentando não ter gostado das atitudes das meninas que não se interessavam pelo jogo, mesmo sem ter testado a nova regra no jogo. Não houve processo de construção da regra com a turma, questionamento sobre dificuldades do jogo ou argumentação sobre a importância daquela(s) regra(s), aspectos importantes para o desenvolvimento da autonomia. A falta de questionamentos sobre o que estava acontecendo no jogo impediu a possibilidade de a turma vivenciar momentos de construção da regra, verificar quais eram as suas necessidades, e entender qual era o sentido da nova regra.

Outra categoria levantada foi: Situações envolvendo questões de gêenero. Gênero pode ser entendido como "a construção social que uma dada cultura estabelece ou elege em relação a homens e mulheres" (SOUSA e ALTMANN, 1999, p. 53). Em alguns momentos, meninos e meninas divergem nas opiniões, preferências e habilidades nas brincadeiras, da mesma forma que diferem entre os colegas do mesmo gênero. Isso é comum, mas o encaminhamento dado pelo professor sobre as atitudes assumidas pelos alunos é que se diferencia.

$\mathrm{O}$ primeiro fato observado aconteceu na $\mathrm{E} 1$ durante a explicação do jogo pela professora, quando a mesma usou um recurso a mais para ilustrar a sua explanação:

\begin{abstract}
Ainda sentada no chão com a turma, ela riscou no chão do pátio, usando giz de lousa, alguns "xis" representando os alunos que estariam jogando, e pegou algumas canetas no seu estojo para fazer a representação do pegador e do fugitivo. Foi cuidadosa em pegar cores diferentes, porém enfatizou no comentário: “- Menino é a azul que será o pegador, menina é a vermelha que será o fugitivo”. (DCE1)
\end{abstract}

Mesmo não tendo gerado discussão entre os alunos, essa questão merece análise devido aos estereótipos de gênero construídos socialmente e muitas vezes repetidos, mesmo que de forma inconsciente, nas práticas cotidianas. A atitude da professora mostra a reprodução de um padrão (azul = menino e vermelho $=$ menina) que reflete valores construídos com base em papéis sociais e fornece amplo campo de discussão na escola.

A EF Escolar tem uma história de separação entre os gêneros em suas aulas. Por muito tempo isso foi comum, e acreditamos que em algumas 
escolas isso ainda permaneça. Sem esquecer os professores que mantêm o grupo de alunos juntos, seguindo orientação da escola, mas fazem essa separação rotineira em suas aulas. A justificativa é, em geral, dada pela superioridade física dos meninos e situação de proteção das meninas, porém, a história é muito mais complexa.

Essa história mostra que na aparência das diferenças biológicas entre os sexos ocultaram-se relações de poder marcadas pela dominação masculina - que mantiveram a separação e a hierarquização entre homens e mulheres, mesmo após a criação da escola mista, nas primeiras décadas deste século. Buscou-se manter a simbologia da mulher como um ser dotado de fragilidade e emoções, e do homem como força e razão, por meio das normas, dos objetos, do espaço físico e das técnicas do corpo e dos conteúdos de ensino, fossem eles a ginástica, os jogos ou - e, sobretudo - os esportes. (SOUSA, ALTMANN, 1999, p.57)

Na nossa sociedade, as mulheres ainda lutam para conseguir os mesmos direitos que os homens e (ainda) são vistas por muitos como frágeis. Esta situação poderia ser aproveitada para o trabalho de valores como igualdade e respeito, embutidos em atitudes sociais.

$\mathrm{Na}$ mesma escola, outro fato foi observado:

A roda foi feita com todos de mãos dadas. Os meninos se concentraram de um lado e as meninas do outro, no encontro dos dois gêneros eles não deram as mãos, porém, mediram o espaço suficiente e já sentaram (sem nenhuma manifestação sobre o não cumprimento da regra. Eles se resolveram sozinhos). (DC-E1)

Ainda nessa escola, a professora realizou uma brincadeira com um aluno envolvendo questões de gênero, o que poderia demonstrar uma atitude preconceituosa, que não contribuiria para a formação moral dos educandos, mas rapidamente houve reconhecimento da colocação equivocada:

[...] ela virou-se e viu que um dos alunos estava fora da fila, e mais para o lado da fila das meninas. Então ela perguntou: “- Fernando, onde você está, está perdido?" Ele riu e falou que estava, ela também riu e disse que estava achando meio estranho. Imediata- 
mente um colega disse, "ele está confuso". A professora virou-se para mim sorrindo e disse que ela faz as brincadeiras e os alunos acabam aprendendo. [...]. (DC-E1)

A professora pediu para que o aluno reconhecesse o seu lugar na fila certa. Mas, qual é a fila certa? Fila de menina e menino, ordem crescente de tamanho e etc. Entendemos que a fila é uma forma de organizar a saída e entrada dos alunos pelos espaços da escola, mas, por que as mesmas devem ser definidas pelo gênero?

$\mathrm{Na}$ situação descrita, a professora abriu margens para que outros questionassem a opção sexual do colega. A própria professora reconheceu que incentivou comentários e julgamentos precipitados, mas não retomou o ponto com a turma.

$\mathrm{Na}$ E2 a divisão das equipes para o jogo foi feita por gênero. " $[$...] nesta atividade a professora disse que separaria meninos das meninas, e chamou dois meninos para escolherem times." (DC-E2)

Se enfatizamos a importância do jogo para a construção dos valores e da moral, principalmente com relação à cooperação e ao respeito ao outro, as atitudes dos professores podem influenciar esse processo de desenvolvimento. "[...] é preciso que o educador proporcione à criança um ambiente adequado para que ela possa fazer as experiências necessárias e construa seus próprios valores morais." (VINHA, 2000, p.41)

A terceira categoria levantada foi: Regras: Cumprimento $x$ Descumprimento, na qual nos reportamos às regras, mas também aos momentos de interferências das professoras observadas. Algumas ações aconteceram por meio do diálogo, a professora mostrou aos alunos o ato de descumprimento e retomou o combinado do jogo com o grupo sem exaltar a falha individualmente, não constrangendo quem errou: “- Professora tem gente saindo do lugar que é água marinha. A professora retomou a regra com a turma toda sem parar o jogo e as crianças se contiveram." (DC-E1)

Sobre o desenvolvimento das situações e as interferências feitas pelas professoras - fato que para Piaget (1977) e Vinha (2000) é ponto relevante para abrir possibilidades para os alunos se resolverem de acordo com o considerado justo, visto que a moralidade não nasce pronta, mas sim, é um processo de construção que poderá levá-los ao respeito mútuo - foi observada a ação da professora citada.

É importante uma reflexão sobre as possibilidades para lidar com conflitos de correntes da situação de jogo, enfatizando a importância da regra.

Pensar a Prática, Goiânia, v. 17, n. 3, p. 783-799, jul./set. 2014 
Regras morais, enquanto normas de ação que dizem respeito ao agir de forma harmônica para os envolvidos, devem validar as relações interpessoais e vincular a obediência ao sentimento de satisfação pessoal em cumpri-la, ao vínculo social e também às conseqüências naturais de não roubar no jogo, não bater no outro, não pegar o que não é seu, não ser escolhido por alguém no time ou ser trapaceado na brincadeira. (SILVA, 2009, p.63)

Os alunos em geral transgridem as regras por falta de informações, por não entenderem o sentido do que está sendo imposto. Característica da fase heterônoma é o cumprimento das regras quando há vigilância, esta é a fase em que muitos dos alunos observados se encontram.

Para a formação do desenvolvimento moral e dos valores é preciso que o grupo construa conjuntamente suas regras, e que estas façam sentido para ele. Além do ambiente cooperativo ser mais um fator a agregar no processo de formação moral do indivíduo, as relações com os pares são relevantes também.

As regras não são meras convenções, e o respeito que o indivíduo adquire por elas é de extrema importância. Sua compreensão e vivência são partes do processo de construção por parte da criança (VINHA, 2000, p.73). Se o grupo as constrói, compreende sua necessidade, consequentemente terá maiores condições de cumpri-las.

O cumprimento das regras é a afirmação de que existem limites e eles são importantes na construção da vida moral dos sujeitos. Durante muitas situações do dia a dia, a criança vive cercada por regras, como no jogo. Quando a regra não é cumprida no jogo, ele não acontece. "A criança constrói regras quando controla seu relacionamento com o outro; sai de si para colocar-se do ponto de vista das ideias e dos sentimentos dos parceiros (reciprocidade)." (FARIA, 1989, p.111)

As professoras observadas retomavam as regras durante os jogos. Aprendendo a obedecer às regras do jogo a criança aprende sobre a necessidade das regras e sobre o respeito também no âmbito social.

As regras servem para definir os limites. Limite se refere até onde podemos chegar. Quais são os limites dos nossos alunos na escola, nas aulas de EF e no jogo? Se não há o estabelecimento de limites e a construção do respeito entre os alunos, o desenvolvimento da moralidade e dos valores pode ficar distante do que eles poderão viver futuramente.

(...) o estabelecimento de limites necessários significa dar a noção de realidade à criança. Esses limites servem de parâmetros para os relacionamentos que se estabelecem,

Pensar a Prática, Goiânia, v. 17, n. 3, p. 783-799, jul./set. 2014 
garantem a justiça, auxiliam a cooperação e a convivência, preparando-a para viver em um mundo real. (VINHA, 2000, p. 52 - 53).

É necessário que o aluno compreenda que as regras são construções coletivas e, caso não concorde, pode contribuir para que seja alterada, de acordo com o grupo.

$\mathrm{Na}$ E3 a professora reforçava em seu discurso a preservação das atitudes dignas entre os alunos, porém, durante o jogo, a turma muito agitada não conseguia relacioná-las com o que estava acontecendo e não colocava em prática o que a professora dizia.

\begin{abstract}
"Rafael fez o gesto que queria antes e não o da professora. Alguns alunos contaram para a professora, e ela disse que aquele gesto não era digno, os alunos deram mais algumas risadas e continuaram a brincadeira proposta pela professora." (DC-E3)
\end{abstract}

Essa professora algumas vezes perdia o controle da turma com o barulho tornando-se excessivo e com brincadeiras fora do contexto da aula. E por mais que o seu discurso fosse adequado, a professora não fazia mediações e usava de ações um pouco mais severas para resolver os conflitos.

Os meninos mais uma vez tentaram driblar a professora saindo sem pedir para beber água. Ela logo percebeu a saída deles e chamou a atenção para voltarem à atividade. Nisso um deles pisou no pé de uma das meninas, essa se irritou, a professora fez o menino pedir desculpas e ordenou que parassem já.(DC-E3)

As regras foram tratadas pela professora de forma autoritária, e, embora ela se esforçasse para controlar a disciplina da turma, isso não acontecia. Algumas regras eram retomadas, mas sem reflexão sobre a sua importância, isso estimula a postura heterônoma nos alunos e os leva a burlar as regras sem a professora perceber. "[...] para o educador não é suficiente exigir obediência em nome de alguma autoridade: ele precisa tornar plausível a legitimidade das normas." (GOERGEN, 2007, p. 751)

Conforme Piaget (1994), a criança nesta faixa etária da observação está no $3^{\circ}$ estágio da consciência das regras, no qual aos poucos a autonomia vai substituindo a heteronomia. A regra do jogo começa a ser tomada pela livre decisão, não mais como algo sagrado e imutável, mas essa mudança depende de estímulos. Contudo, nas aulas assistidas, o cumprimento deu-

Pensar a Prática, Goiânia, v. 17, n. 3, p. 783-799, jul./set. 2014 
se por uma ação de controle externo. Não houve questionamento dos alunos e nem abertura para mudanças, assim, mesmo coagidos pela regra imposta e sem compreender o seu sentido, alguns alunos a burlavam.

É relevante que os professores percebam a necessidade da existência das normas e do respeito, sendo importantes para relações harmoniosas com o grupo. Lukjanenko (1995, p.18) nos afirma que "quando a criança descobre a verdade necessária nas relações de respeito mútuo, já está a caminho da autonomia, pois a verdade dos fatos deixará de ser imposta externamente, mas será compreendida pela consciência pessoal."

Guirra e Prodócimo $(2009$, p.10) demonstram a figura do professor e seu papel:

\begin{abstract}
Intermediar essas negociações para que ninguém seja excluído e fique de fora das aulas e das brincadeiras. Essa intervenção do professor, no sentido de garantir a inclusão, tende a ensinar as crianças, já nos primeiros anos de vida, a importância de viver em sociedade, revendo valores deturpados que permeiam essa situação, e como a escola pode contribuir com esse quadro.
\end{abstract}

Outra categoria levantada foi Postura dos alunos. Essa categoria foi baseada na forma como os alunos se relacionam, alterando o desenvolvimento da aula.

[...] havia uma única menina (Marli) que chutava, disputava a posse de bola com os meninos e partia para o ataque sem medo, organizava o sistema do seu time, ou pelo menos, tentava organizar. As meninas não se importavam, e tentavam fazer o que Marli dizia, porém com os meninos nem sempre era assim. (DC-E2)

No jogo é possível o aparecimento de líderes e isso pode ser tratado pelos professores. Nem sempre a pessoa mais habilidosa se torna líder, existem diferentes formas de liderança. "Liderança pode ser entendida pela interação entre a personalidade do indivíduo e a situação, já que toda a situação exige talentos especiais para enfrentá-la e resolver problemas advindos desta mesma situação." (VENDITTI, WINTERSTEIN, 2005, p.10)

O educador que possibilitar a canalização das características de um líder vai estimular os pontos positivos como o saber ouvir os integrantes do grupo, para que se organize a melhor resolução de qualquer situação, a partir dos fatos colocados pelos integrantes e da coordenação do líder. 
[...] pode-se aproveitar da liderança de alguns alunos para trabalhar o respeito e a distribuição de funções entre eles. Cada um possui um papel dentro do grupo, e ainda que numa relação de competição, um depende do outro para realizar a tarefa e denotar um sentido na atividade proposta. (BUSCH, 2010, p.44)

Vinha (2000, p. 84), em seus estudos, deixa claro que "a criança entra no mundo da moralidade a partir da autoridade, legitimando as normas oriundas da pessoa que ela admira e, posteriormente, pelo contrato proveniente das relações com iguais". No caso relatado não houve trabalho de estímulo à liderança. $\mathrm{O}$ professor é essencial para a condução das discussões, chamando sempre os alunos à busca pela cooperação e ao que é justo para todos. “(...) as noções racionais do justo e do injusto tornam-se reguladoras do costume, porque estão implicadas no próprio funcionamento da vida social entre iguais (...)" (Piaget, 1994, p.67)

Em outra situação observada:

Marli gritou com uma das meninas, a colega respondeu: “- Marli! Estou cansada de você querer mandar em tudo, estou bem cansada!" A colega contou para a professora que não gostava daquela situação e a Marli argumentou que elas só ficavam bebendo água, não sendo possível jogar. A professora apenas mandou a aluna voltar ao jogo. Marli continuava ditando as regras."(DC-E2)

A professora não interrompeu a forma de comando da aluna, nem disse à classe que aceitava sugestões para o jogo, assim, os alunos, nas suas limitações, tentavam seguir o proposto para a aula. As propostas não incluíam reflexão sobre os pontos observados nas aulas, e quando aparecia algum tipo de situação que dificultava as ações ou motivava uma discussão havia certa omissão por parte da professora. Não havia troca e nem análise dos fatos envolvidos nas situações, não contribuindo assim para a construção da cooperação e autonomia dos alunos. Para Piaget (1994, p.82):

Conforme a cooperação substitui a coação, a criança dissocia seu eu do pensamento de outro. Com efeito, quanto mais cresce, menos sofre o prestígio do mais velho, mais discute de igual para igual e mais oportunidade tem de livremente opor, além da obediência, da sugestão ou do negativismo, seu ponto de vista ao ponto de qualquer outro: desde então, não só descobre a fronteira entre o eu e o 
outro, como aprende a compreender o outro e a se fazer compreender por ele.

O momento de reflexão não apareceu nas aulas, nem por parte da professora que podia mediar e auxiliar os alunos nos conflitos, e nem por parte dos alunos que seguiam da maneira que achavam melhor, sem se colocarem no lugar do outro. Aulas, jogos e situações cotidianas propiciam momentos que permitem repensar e tomar providências para melhorar ou sanar desconfortos. Aulas desafiadoras poderão ser o trampolim para ativar nos alunos a vontade de buscar, conhecer e conseguir superar as dificuldades cada vez mais.

Cruz (2006) narrou situações de exclusão de dois alunos e descreveu as atitudes e comportamentos dos colegas de classe em relação a isso. $\mathrm{O}$ autor afirma que as diferenças presentes entre os alunos serviram para considerar e expressar que as pessoas são diferentes e vivem de formas diferentes, que não existe um único padrão, e sim, vários possíveis padrões, e que muitos dos professores não trabalham com essas situações.

$\mathrm{Na}$ E2 a turma rejeitava os comandos dados pela colega, mostrando que ela também não pertencia a nenhum grupo por mais hábil que fosse.

O caminho para as ressignificações e compreensões das diferenças é movediço e propenso a certas armadilhas. Ou seja, se não consideradas com certo "cuidado", correse risco de banalização dos "outros", relativismos extremos, universalismos absolutos, ou novas submissões e subjugações. (CRUZ, 2006, p.94)

O professor deve dar espaço para os alunos elaborarem, criarem, construírem, discutirem as regras do jogo nas aulas. A partir do momento que as crianças perceberem suas possibilidades de criar e modificar as regras com o consenso de todos, poderão transferir esses conceitos para a prática das regras sociais; saem do mundo do jogo e entram no mundo real.

\section{Considerações Finais}

Buscamos neste artigo mostrar o jogo na educação e sua importância no desenvolvimento moral.

Nossas inquietações foram respondidas, a princípio, afirmando como as regras dos jogos são tratadas durante as aulas com uma grande imposição. Há unanimidade na forma com que os professores ditam o que deve ser feito nos jogos.

Pensar a Prática, Goiânia, v. 17, n. 3, p. 783-799, jul./set. 2014 
Com as categorias levantadas refletimos que o jogo pode ser essencial para o desenvolvimento moral dos educandos, porque suas vivências permitem com que os seus participantes discutam e reflitam (suas regras), vivenciem todas as possibilidades de atividades, respeitem o seu colega oponente e as regras que regem aquele movimento (chamado jogo).

É necessário um ambiente sócio-cooperativo bem construído, isso somado ao estímulo dos professores às reflexões diárias, ao respeito às diferenças e a uma maior tolerância também poderá influenciar diretamente na construção de indivíduos mais humanos.

É de suma importância que os alunos participem da elaboração das regras e normas que envolvem as atividades das aulas e a convivência em grupo. Fica bem mais difícil exigir o cumprimento de algo que não se entende o porquê de existir. Assim, partimos da hipótese que os alunos engajados no trabalho e na convivência em grupo também sofrerão mudanças de postura para, num futuro bem próximo, serem pessoas mais justas e tolerantes.

Cada vez mais a educação formal deve englobar todos os âmbitos na formação de suas crianças, seus educandos, por mais que haja a especificidade das disciplinas. Sabemos também que as pesquisas não podem cessar, e a melhora nas posturas e vivências da sala de aula muito menos, nem no âmbito da moralidade e muito menos na área da Educação Física. Elas devem prosseguir, serem levadas e transformadas no dia a dia da escola, para que outros pesquisadores/educadores saiam em busca de novas conquistas com o propósito de melhorar, mesmo que de gota a gota, a EDUCAÇÃO nas nossas aulas.

\title{
THE GAME IN PHYSICAL EDUCATION CLASSES AND THEIR IMPLI- CATIONS ON MORAL DEVELOPMENT
}

\begin{abstract}
This work investigated the development of the game in Physical Education classes in groups of the 5th year of elementary school in the municipality of Valinhos-SP, and his contributions to the development of morality in students. Qualitative research was carried out. Through classroom observations it was noted that the game was worked in different approaches. The teachers dealt with the rules in a more or less directive way, and its exposure with little or no opening for students, but there were no interventions were made use of opportunities to encourage students ' moral development. It was considered that even the game being treated in class, the opportunities offered to students ' moral development have been little exploited.
\end{abstract}

Pensar a Prática, Goiânia, v. 17, n. 3, p. 783-799, jul./set. 2014 
Keywords: School. Physical Education. Game. Moral Development. Interpersonal Conflicts.

\section{EL JUEGO EN LAS CLASES DE EDUCACIÓN FÍSICA Y SUS IMPLICA- CIONES EN EL DESARROLLO MORAL}

\section{Resumen}

Este trabajo investiga el desarrollo del juego en las clases de Educación Física en grupos de $5^{\circ}$ año de escuela primaria en el municipio de Valinhos-SP y sus contribuciones al desarrollo de la moralidad en los estudiantes. Se realizó la investigación cualitativa. A través de observaciones de aula se observó que el juego fue trabajado en diferentes enfoques. Los profesores tratado con las reglas más o menos em forma directiva, y su exposición con poca o ninguna apertura para los estudiantes, pero hubo intervenciones no se hicieron uso de oportunidades para fomentar el desarrollo moral de los estudiantes. Se consideró que incluso el juego siendo tratado en clase, las oportunidades que se ofrecen para el desarrollo moral de los estudiantes han sido poco explotadas.

Palabras-claves: Educación Física de la Escuela. Juego. Desarrollo Moral. Conflictos Interpersonales.

\section{Referências}

BROUGÈRE, G. Que possibilidades têm a brincadeira? In: BROUGÈRE, G. Brinquedo e cultura. Revisão técnica e versão brasileira adaptada por Gisela Wajskop. 4ª ed. São Paulo: Cortez, p. 89-107, 2001.

BUSCH, A. M. Análise das manifestações agressivas nas aulas de educação física do ensino fundamental II. 2010. 88 f. Graduação (Trabalho de Conclusão de Curso em Educação Física) - Faculdade de Educação Física, UNICAMP. Campinas, SP, 2010.

BUXARRAIS, M. R. Actitudes, valores y normas: aprendizaje y desarrollo moral. Comunicación, Lenguaje y Educación, Barcelona, 1992.

CRUZ, R. Educação física, escola e cultura: o enredo das diferenças. 2006. 101 f. Dissertação (Mestrado em Educação Física) - Faculdade de Educação Física, UNICAMP, Campinas, SP, 2006.

FARIA, A. R. de. Desenvolvimento da criança e do adolescente segundo Piaget. São Paulo: Ática, 1989. 
FREIRE, J. B. Da escola para a vida. In: VENÂNCIO, S. \& FREIRE, J. B. (org.). O jogo dentro e fora da escola. (Coleção educação física e esportes) Campinas, SP: Autores Associados, 183p, 2005.

GUIRRA, F. J. S.; PRODOCIMO, E. A criança e o jogo: um olhar sobre formas de negociação. Revista Iberoamericana de Educación, ISSN: 16815653, n. 49/1, 25 mar., 2009.

GOERGEN, P. Educação e valores no mundo contemporâneo. Educação e Sociedade, Campinas, vol. 26, n. 92, p. 983-1011, Especial, Out., 2005. Disponível em <http://www.cedes.unicamp.br>. Acesso em: 15 jun 2013.

. Educação moral hoje: Cenários, perspectivas e perplexidade. Educação e Sociedade: Cedes, Campinas, v.28, n.100, Especial, p.737-762, 2007.

HUIZINGA, J. Homo Ludens: O jogo como elemento da cultura. São Paulo: Ed. Perspectiva, 243p, 1980.

LOMBARDI, J. C. \& GOERGEN, P. (orgs.). Ética e educação: reflexões filosóficas e históricas. Campinas, SP: Autores Associados, 2005.

LUKJANENKO, M. F. S. P. Um estudo sobre a relação entre o juízo moral do professor e o ambiente escolar por ele proporcionado. 1995. $167 \mathrm{f}$. Dissertação (Mestrado em Educação) - Faculdade de Educação, UNICAMP, Campinas, SP, 1995.

MARQUES, M. N.; KRUG, H. N. O jogo como conteúdo da Educação Física Escolar. P@rtes, São Paulo, v.00, p. eletrônica. Jul., 2009. Disponível em: http://www.partes.com.br/educacao/ojogocomoconteudo.asp.asp. Acesso em: 20 maio 2013.

MINAYO, M. C. de S. (org.). Pesquisa Social: teoria, método e criatividade. 29. ed. Petrópolis. Rio de Janeiro: Vozes, 108p, 2010.

PALMA, A. P. T. V.; SILVA, L. C. F. Os conflitos interpessoais e as aulas de educação física: perspectivas para a construção da autonomia. In: I COPPEM, 2009, Campinas: Faculdade de Educação, UNICAMP, p. 54, 2009.

PIAGET, J. O juízo moral na criança. São Paulo: Summus Editorial, 1994.

Pensar a Prática, Goiânia, v. 17, n. 3, p. 783-799, jul./set. 2014 
SEVERINO, A. J.; Educação e ética no processo de construção da cidadania. In: LOMBARDI, J. C. \& GOERGEN, P. (orgs.). Ética e educação: reflexões filosóficas e históricas. Campinas, SP: Autores Associados, 179p, 2005 .

SILVA, L. C. F. da. Intervenções em situações de conflitos interpessoais nas aulas de educação física. 2009. 207 f. Dissertação (Mestrado em Educação) - Centro de Educação, Comunicação e Artes. UEL, Londrina, Paraná, 2009.

SOUSA, E. S. de; ALTMANN, H. Meninos e meninas: Expectativas corporais e implicações na educação física escolar. Educação e Sociedade: Cedes, Campinas, v. XIX, n. 48, ago., 1999.

VINHA, T. O educador e a moralidade infantil numa perspectiva construtivista. Revista do Cogeime, no 14, jul., 1999.

O desenvolvimento da moralidade segundo Jean Piaget. In: O educador e a moralidade infantil numa perspectiva construtivista. Campinas, SP: Mercado das Letras; São Paulo: FAPESP, p.37-131, 2000.

As regras e a autoridade do educador. In: O educador e a moralidade infantil numa perspectiva construtivista. Campinas, SP: Mercado das Letras; São Paulo: FAPESP, p.241-275, 2000.

A linguagem do educador. In: O educador e a moralidade infantil numa perspectiva construtivista. Campinas, SP: Mercado das Letras; São Paulo: FAPESP, p.277-338, 2000.

Recebido em: 13/08/2013

Revisado em: 08/10/2013

Aprovado em: 22/12/2013

Endereço para correspondência:

alecaetano99@hotmail.com

Alessandra Caetano

Serviço Social da Indústria , Centro Educacional, SESI 299.

Pensar a Prática, Goiânia, v. 17, n. 3, p. 783-799, jul./set. 2014 
Rua Clovis Bevilacqua, 15

Bela Vista

13270300 - Valinhos, SP - Brasil

Pensar a Prática, Goiânia, v. 17, n. 3, p. 783-799, jul./set. 2014 